\title{
Sleep-wake cycle irregularities in type 2 diabetics
}

\author{
Tomoko Nakanishi-Minami ${ }^{1}$, Ken Kishida ${ }^{1,2^{*}}$, Tohru Funahashi ${ }^{1,2}$ and lichiro Shimomura ${ }^{1}$
}

\begin{abstract}
Background: The incidence of type 2 diabetes mellitus (T2DM) has been increasing in recent years. Sleep loss and circadian rhythm abnormalities are thought to be one of the underlying causes of adverse metabolic health. However, little is known about sleep-wake cycle irregularities in T2DM. The present study compared the bedtime, waking time, and estimated sleep duration between T2DM and non-T2DM subjects.

Methods: The study subjects were 106 consecutive outpatients with lifestyle-related diseases (males/females $=56 / 50$ ), who answered a questionnaire on sleep status. Subjects were divided into two groups; non-T2DM $(n=32)$ and T2DM ( $n=74)$ subjects.

Results: T2DM subjects retired to bed on weekdays and holidays significantly later than non-T2DM subjects (23:43 versus 22:52, $p=0.0032 ; 23: 45$ versus $22: 53, p=0.0038$, respectively), and woke up significantly later on weekdays and holidays, compared with non-T2DM subjects (06:39 versus $06: 08, p=0.0325 ; 06: 58$ versus $06: 24, p=0.0450$, respectively). There was no significant difference in the estimated sleep duration between the two groups. Daytime sleepiness was reported significantly more commonly by T2DM subjects than non-T2DM subjects ( $p=0.0195)$.
\end{abstract}

Conclusions: Sleep-wake cycle irregularities are more common in T2DM subjects than non-T2DM. Confirmation that such irregularity plays a role in the metabolic abnormalities of T2DM requires further investigation in the future.

Trial registration: UMIN 000002998

Keywords: Bed-time, Awakening-time, Sleep duration, Diabetes

\section{Background}

The etiology of type 2 diabetes mellitus (T2DM) includes both genetic and environmental factors. The incidence of T2DM has been increasing recently mainly due to changes in lifestyle, such as over-eating, physical inactivity, and sleep deprivation. Sleep is a highly active and dynamic process, and serves immune defense in particular, with an important role in disease resistance [1]. Several studies have reported major differences in the frequency of sleep disturbances between diabetics and non-diabetics $[2,3]$. Patients with T2DM sleep less than the general population [4]. The recent dramatic increase in the incidence of obesity and diabetes, and the close relationship between sleep cycles and diabetes [5], suggest detrimental deprivation of certain sleep stages [6,7]. The endogenous circadian clock, including the suprachiasmatic nucleus $(\mathrm{SCN})$ in the hypothalamus and peripheral oscillators in

\footnotetext{
* Correspondence: kkishida@imed2.med.osaka-u.ac.jp

'Department of Metabolic Medicine, Graduate School of Medicine, Osaka University, Suita, Osaka 565-0871, Japan

${ }^{2}$ Department of Metabolism and Atherosclerosis, Graduate School of

Medicine, Osaka University, 2-2 B-5, Yamada-oka, Suita, Osaka 565-0871, Japan
}

vital organs, regulates much of our physiology and behavior across the 24-h day when it is properly aligned with the sleep-wake cycle. The SCN regulates the circadian rhythms in glucose, corticosteroids, leptin and cardiovascular systems through neural and/or humoral signals to the pancreas, liver, adrenal glands, adipose tissues and heart [8]. Shift work is associated with chronic misalignment between the endogenous circadian timing system and behavioral cycles, including sleep-wake and fasting-feeding cycles $[9,10]$. Therefore, health problems are not uncommon in shift workers [11]. Chronic circadian misalignment has been proposed to correlate with metabolic and cardiovascular dysfunction [12-16]. However, whether disruption of the sleep-wake pattern, i.e., sleep-wake cycle irregularity, relates to T2DM remains to be elucidated.

The present study compared the sleeping and waking times in subjects with and without T2DM.

\section{Methods \\ Participants}

Subjects were recruited from consecutive Japanese outpatients with metabolic lifestyle-related diseases (e.g., 
hypertension, dyslipidemia, diabetes and/or gout/ hyperurecemia), who visited the Department of Metabolic Medicine, Osaka University Hospital, between October and December 2011, and answered a questionnaire on sleep status. The exclusion criteria included pregnant women, nursing mothers, and nighttime and/ or shift workers. Disease-related exclusion criteria included pituitary diseases, mental disorders, and malignant diseases. The study subjects were 106 consecutive outpatients (males/females $=56 / 50$ ). The study was approved by the Medical Ethics Committee of Osaka University. All participants were Japanese and each gave a written informed consent. This study (The EndocrineMetabolic Disease and Sleep Apnea Syndrome Study) is registered under number UMIN 000002998 https://upload. umin.ac.jp/cgi-open-bin/ctr/ctr.cgi?function=brows\&action $=$ brows \& type $=$ summary\&recptno=R000003635\&language $=\mathrm{E}$.

\section{Self-questionnaire on sleep habits}

The questionnaire on sleep patterns consisted of the following 8 questions: bedtime on weekdays and holidays (at half-hour intervals); waking time on weekdays and holidays (at half-hour intervals); arousal (yes or no); daytime sleepiness (yes or no); insomnia due to work (yes or no); insomnia due to mental stress (yes or no). Sleep duration (hours) $=$ waking time - bedtime.

\section{Anthropometric data and laboratory tests}

Height $(\mathrm{cm})$, weight $(\mathrm{kg})$, and body mass index (BMI) in $\mathrm{kg} / \mathrm{m}^{2}$ were measured in the standing position. Systolicand diastolic- blood pressures were measured with a standard sphygmomanometer after at least 5-min rest. After overnight fasting, venous blood samples were collected while the subject was in the supine position for measurements of blood glucose, glycoalbumin, hemoglobin A1c (HbA1c), triglyceride, high-density lipoproteincholesterol (HDL-C), uric acid, and creatinine. Lowdensity lipoprotein-cholesterol (LDL-C) was calculated with the Friedewald equation. The value for HbA1c (\%) was estimated as National Glycohemoglobin Standardization Program (NGSP) equivalent value (\%), calculated by the formula HbA1c $(\%)=$ HbA1c (Japan Diabetes Society [JDS], $\%)+0.4 \%$.

Diabetes mellitus was defined according to the criteria of the World Health Organization and/or current treatment for diabetes mellitus (sulfonyl ureas/biguanides/ $\alpha$-glucosidase inhibitors/pioglitazone/ dipeptidyl peptidase-4 inhibitors/ glinides/insulin/glucagon-like peptide-1 analogue, $n=28$ / 27/23/10/14/2/17/2). Diabetic retinopathy, nephropathy

Table 1 Baseline characteristics of subjects with type 2 diabetes mellitus and control subjects $(n=106)$

\begin{tabular}{|c|c|c|c|}
\hline & Control subjects $(n=32)$ & T2DM subjects $(n=74)$ & $\mathrm{p}$ value \\
\hline Gender, male/female & $19 / 13$ & $37 / 37$ & 0.4041 \\
\hline Age, years & $62 \pm 1(39-83)$ & $66 \pm 1(36-84)$ & 0.5349 \\
\hline Job type(non/employee/individual proprietor/homemaker/others) & $5 / 14 / 1 / 11 / 1$ & $17 / 25 / 1 / 27 / 4$ & \\
\hline Body mass index, $\mathrm{kg} / \mathrm{m}^{2}$ & $22.7 \pm 0.7(13.9-30.8)$ & $24.7 \pm 0.5(17.8-34.5)$ & 0.0153 \\
\hline Blood glucose, mg/dL & $94 \pm 3(53-113)$ & $128 \pm 74(52-252)$ & $<0.001$ \\
\hline Glycoalbumin, \% & $14.9 \pm 1.0(12.9-16.0)$ & $19.8 \pm 0.6(12.5-33.3)$ & 0.0243 \\
\hline HbA1c (NGSP), \% & $5.9 \pm 0.1(5.4-6.3)$ & $7.0 \pm 0.1(5.6-14.4)$ & 0.0001 \\
\hline Systolic blood pressure, $\mathrm{mmHg}$ & $138 \pm 23(98-174)$ & $137 \pm 2(101-182)$ & 0.9149 \\
\hline Diastolic blood pressure, $\mathrm{mmHg}$ & $81 \pm 2(65-97)$ & $80 \pm 1(49-105)$ & 0.7800 \\
\hline Triglyceride, mg/dL & $175 \pm 41(44-1231)$ & $138 \pm 10(34-471)$ & 0.8158 \\
\hline High-density lipoprotein cholesterol, mg/dL & $62 \pm 23(31-121)$ & $53 \pm 2(17-103)$ & 0.0079 \\
\hline Low-density lipoprotein cholesterol, mg/dL & $117 \pm 5(80-196)$ & $112 \pm 4(64-208)$ & 0.3333 \\
\hline Uric acid, mg/dL & $5.5 \pm 0.2(2.8-7.8)$ & $5.5 \pm 0.2(2.7-9.4)$ & 0.9827 \\
\hline Creatinine, mg/dL & $0.70 \pm 0.02(0.46-1.15)$ & $0.86 \pm 0.05(0.44-2.83)$ & 0.0798 \\
\hline Diabetic neuropathy & - & $n=15$ & \\
\hline Diabetic retinopathy (NDR/SDR/PDR) & - & $n=56 / 6 / 12$ & \\
\hline Diabetic nephropathy (stage I/I/III/IV) & - & $n=57 / 9 / 3 / 5$ & \\
\hline Drugs for diabetes (medication/insulin) & - & $n=57 / 17$ & \\
\hline Hypertension (under medications) & $n=18(n=11)$ & $n=60(n=46)$ & 0.0151 \\
\hline Dyslipidemia (under medications) & $n=21(n=13)$ & $n=48(n=34)$ & 0.8253 \\
\hline Insomnia, under medications & $n=6$ & $n=11$ & 0.7736 \\
\hline
\end{tabular}

Data are mean \pm SEM or $n$ (range). Significant level was set at $\mathrm{p}$ value $<0.05$ (bold type). T2DM: type 2 diabetes mellitus, NDR: non-diabetic retinopathy, SDR: simple diabetic retinopathy, PDR: proliferative diabetic retinopathy. 
and peripheral neuropathy were diagnosed as reported previously [17]. Dyslipidemia was defined as total cholesterol of $\geq 220 \mathrm{mg} / \mathrm{dL}$, triglyceride $\geq 150 \mathrm{mg} / \mathrm{dL}, \mathrm{HDL}-\mathrm{C}<40 \mathrm{mg} /$ $\mathrm{dL}$, and/or current treatment for dyslipidemia (statins/ fibrates/ezetimibe; $n=40 / 4 / 5)$. Hypertension was defined as systolic blood pressure $\geq 140 \mathrm{mmHg}$, diastolic blood pressure $\geq 90 \mathrm{mmHg}$, or current treatment for hypertension (calcium channel antagonists/angiotensin converting enzyme inhibitors/angiotensin receptor blockers/ $\beta$-blockers $/ \alpha$ blockers/diuretics/ direct renin inhibitor; $\mathrm{n}=35 / 5 / 36 / 8$ / 2/9/2).

\section{Statistical analysis}

All values were expressed as mean \pm SEM. In all cases, a $p$ value $<0.05$ denoted the presence of a statistically significant difference. Differences between two groups were compared by unpaired Student's $t$-test. Differences in frequencies were compared by the $\chi^{2}$ test. All analyses were performed with the JMP Statistical Discovery Software 9.0 (SAS Institute, Cary, NC).

\section{Results}

Characteristics of T2DM and non-T2DM subjects

Subjects with lifestyle-related diseases were divided into two groups; with T2DM and non-T2DM. The baseline characteristics of the two groups are listed in Table 1. T2DM subjects had significantly higher BMI, lower serum HDL-C levels, higher prevalence of hypertension, than non-T2DM subjects.

\section{Bedtime, waking time, and sleep duration}

Figure 1 is a histogram of reported bedtime on weekdays and holidays in T2DM and non-T2DM subjects. The bedtime on weekends and holidays was significantly later in T2DM subjects, compared to non-T2DM subjects $(23: 43 \pm 0: 12$ versus $22: 52 \pm 0: 13, p=0.0032$, Figure $1 \mathrm{~A}$; $23: 45 \pm 0: 12$ versus $22: 53 \pm 0: 13, p=0.0038$, Figure $1 B$ ).

Figure 2 is a histogram of waking time on weekdays and holidays in T2DM and non-T2DM subjects. The waking time was significantly later in T2DM subjects on weekends and holidays, compared to non-T2DM subjects (06:39 $\pm 0: 08$ versus 06:08 $\pm 0: 02, p=0.0325$, Figure $2 \mathrm{~A} ; 06: 58$ $\pm 0: 08$ versus $06: 24 \pm 0: 12, p=0.0450$, Figure $2 B$ ).

There was no significant difference in the estimated sleep duration on weekdays and holidays between the two groups (Figure 3).

\section{Correlation between sleep-wake parameters and $\mathrm{HbA} 1 \mathrm{c}$}

In bedtime analysis, the lowest HbA1c levels were $6.5 \pm$ $0.1 \%$ and $6.6 \pm 0.1 \%$ recorded at bedtime 23:00-00:00 on weekdays and on holidays, respectively (Figure 4 left, solid box). In waking time analysis, the lowest HbA1c levels were $6.7 \pm 0.1 \%$ and $6.6 \pm 0.1 \%$ in waking time $<06: 00$ on weekdays and holidays, respectively (Figure 4
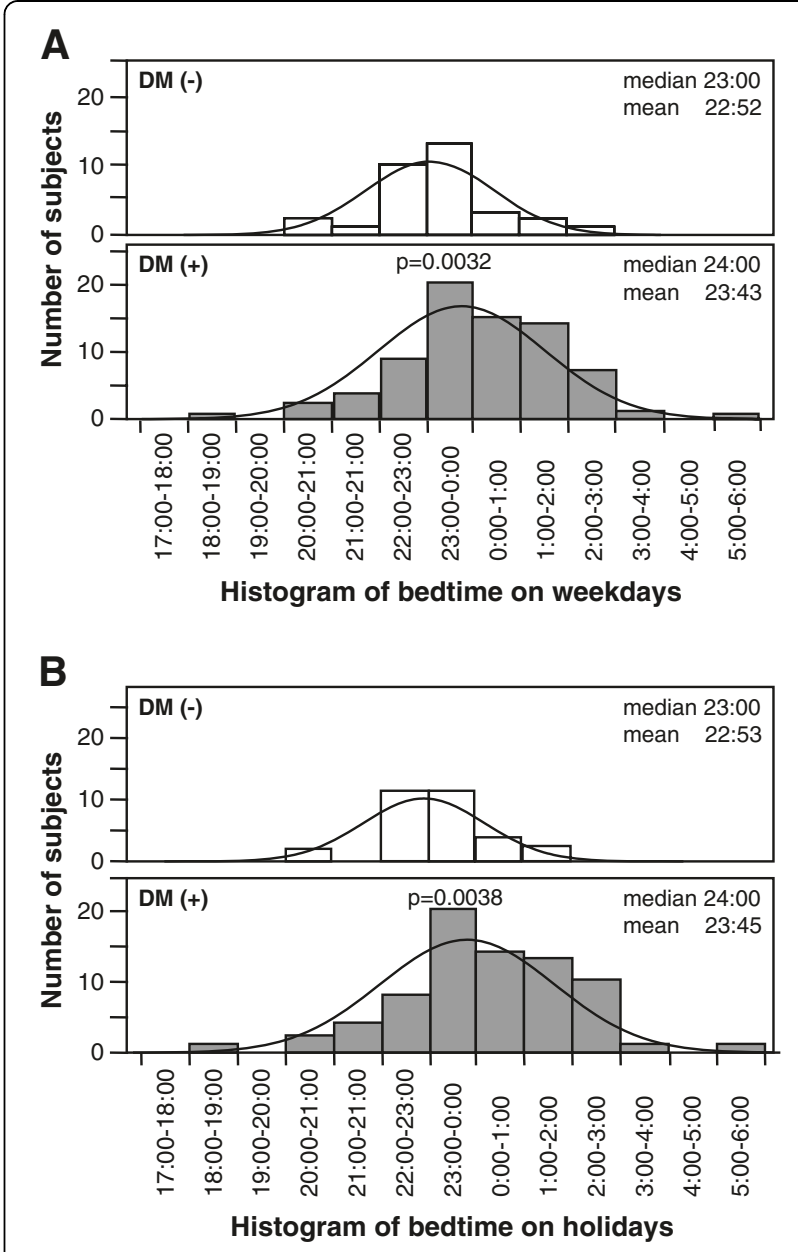

Figure 1 Histograms of the numbers of subjects with type 2 diabetes mellitus (DM+) and non-diabetic subjects (DM-) for each bedtime on (A) weekdays and (B) holidays.

middle, solid box). In sleep duration analysis, the lowest HbA1c levels were $6.4 \pm 0.1 \%$ and $6.4 \pm 0.2 \%$ in subjects who slept for 7-8 h on weekdays and holidays, respectively (Figure 4 right, solid box).

\section{Incidence of sleep-related problems}

The prevalence of daytime sleepiness was significantly higher in T2DM subjects than in non-T2DM subjects ( $46 \%$ versus $22 \%, p=0.0195$, Figure 5 ). However, there were no significant differences in the frequency of arousals at night or percentages of subjects with work- and mental stress-related insomnia between the two groups.

\section{Discussion}

The major findings of the present study were that T2DM subjects retired to bed later and woke up later, and suffered from daytime sleepiness, compared with nonT2DM subjects. The 2006 Ministry of Internal Affairs and Communications (Sōmu-shō) Survey on Time Use 


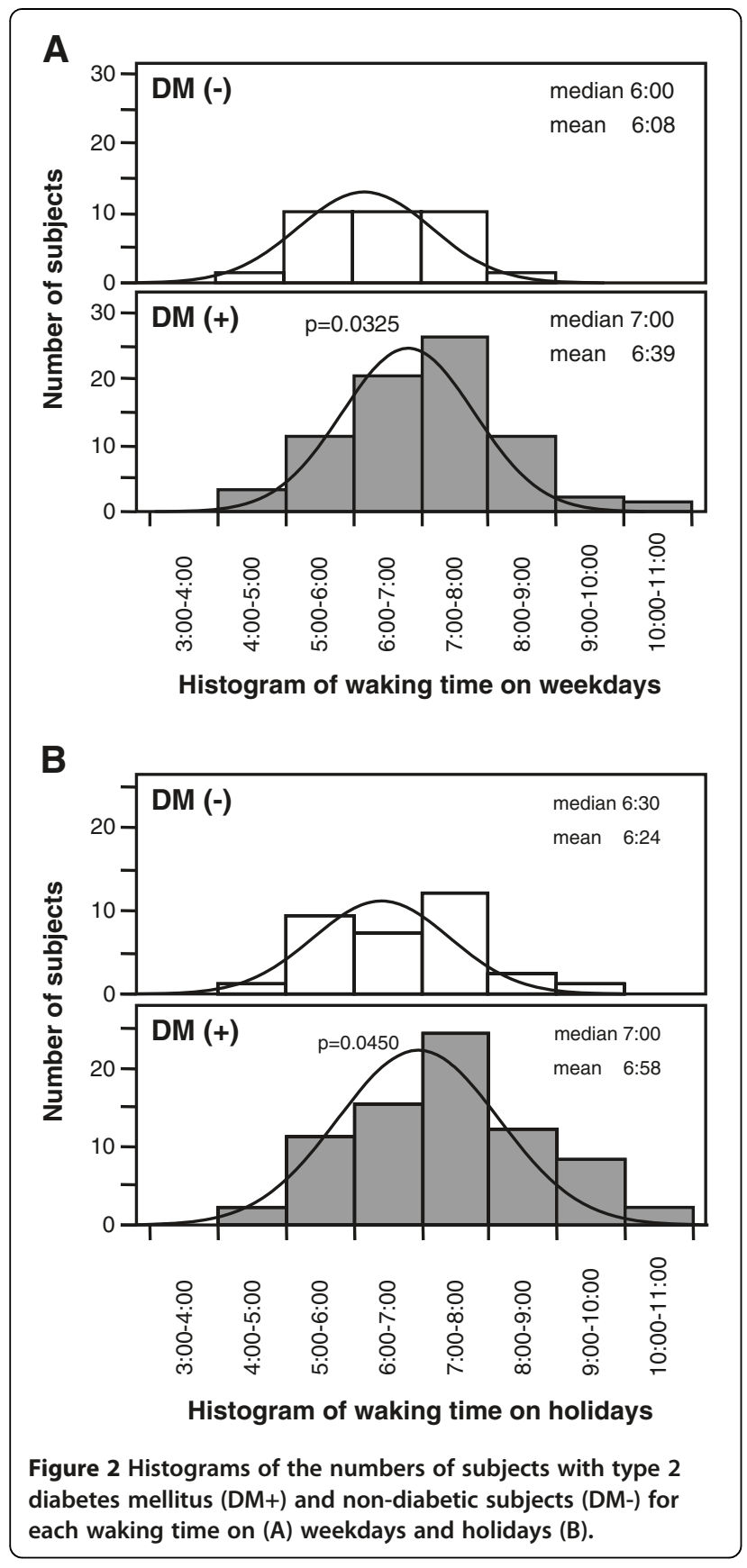

and Leisure Activities indicates that the average bedtime of 66,428 Japanese (males/females; 31,520/34,908) is 23:16 on weekdays, with waking time on weekdays of 06:39. Comparison of the above data and the present findings confirm that the Japanese T2DM subjects tended to retire to bed relatively later than the rest of the population.

The circadian system is linked to various processes that control both sleep and metabolism. The sleep-wake cycle and fasting-feeding behavior are considered to be regulated by the circadian clock [14-16]. Experimental

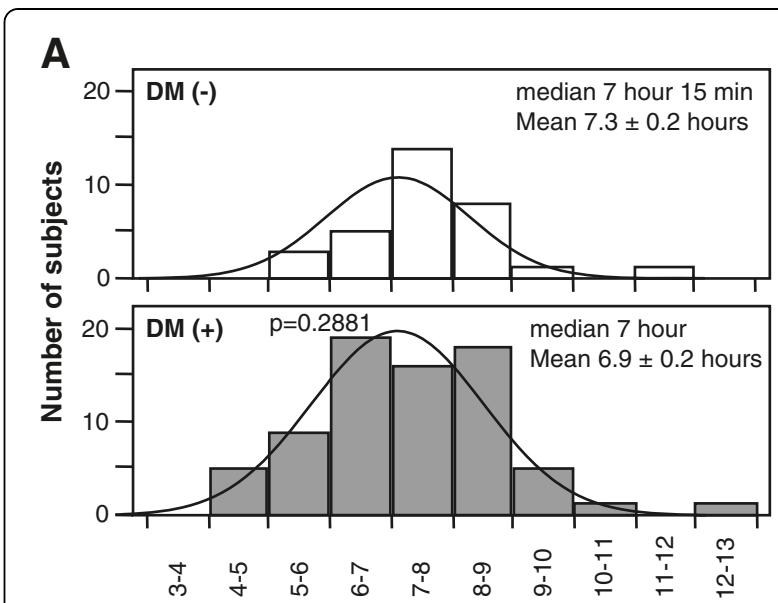

Histogram of sleep duration on weekdays (hours)

B

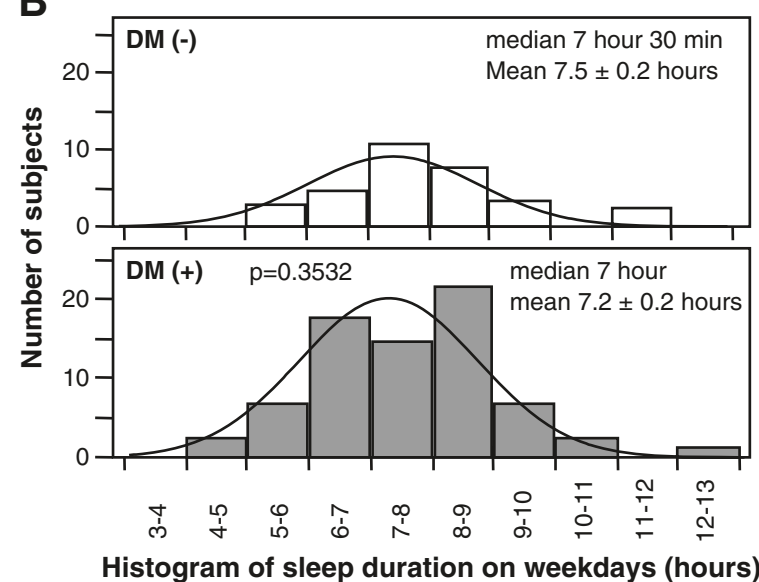

Figure 3 Histograms of the numbers of subjects with type 2 diabetes mellitus (DM+) and non-diabetic subjects (DM-) for different sleep durations on (A) weekdays and (B) holidays.

models of the clock gene have demonstrated the development of metabolic disorders, such as obesity and T2DM, after disruption of the circadian rhythms [18-22]. However, whether abnormal glucose metabolism has any impact on the circadian rhythm remains unclear. A vicious cycle may ensue in the disrupted glucose metabolic pathways, leading to lengthening of the circadian oscillation abnormality. Scheer et al. showed that diurnal variation of neurohumoral factors, such as leptin and cortisol, plays a role in behavioral cycles (fasting/feeding and sleep/wake cycles) [13]. Further studies are required to investigate circadian variation of neurohumoral factors in blood. In this regard, the present work is a crosssectional study, making it difficult to establish a causeeffect relationship. Sleep management, e.g., lifestyle modification by trained medical staff and use of exogenous melatonin as a potential chronotherapeutic agent, may be important to improve the disrupted cardiometabolic 


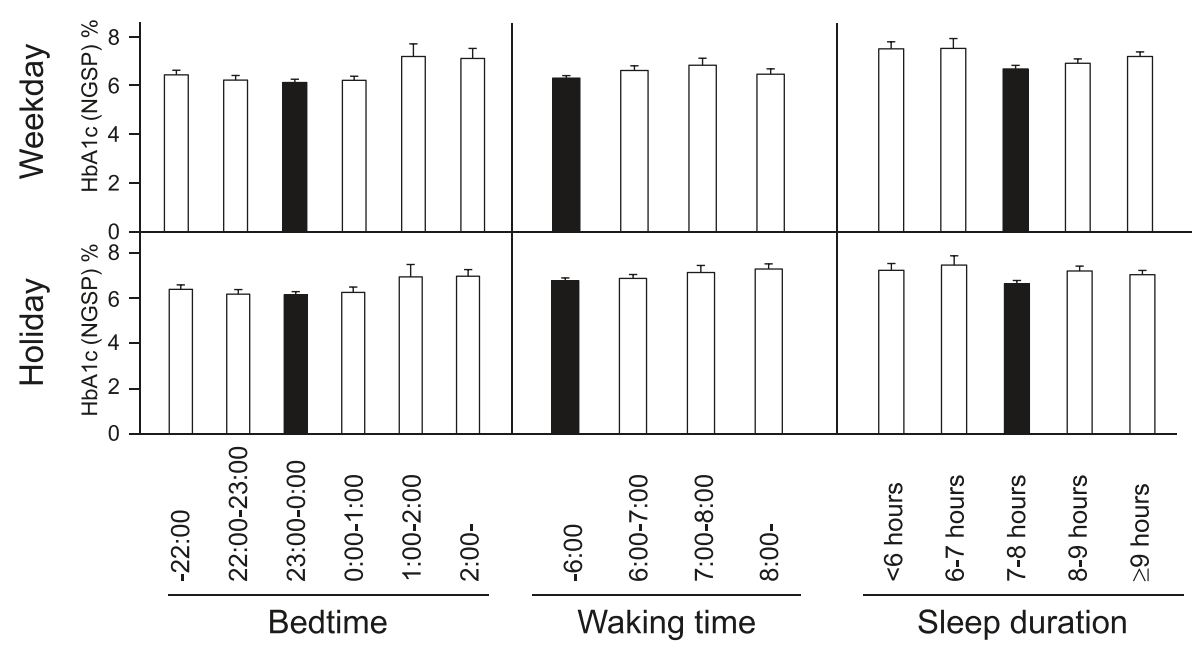

Figure 4 Mean HbA1c levels at various bed and waking times, and according to sleep duration on weekdays (top) and holidays (bottom). Data are mean \pm SEM.

system in T2DM subjects with sleep-wake irregularities. Further prospective interventional studies should be conducted in the future to investigate this relationship.

Patients with T2DM sleep less than the general population [4]. A gradual decrease in self-reported sleep duration seems to have occurred with the dramatic recent increase in the incidence of obesity and diabetes, including a close relationship between sleep cycle and diabetes [23-25]. However, the present study found no significant difference in the sleep duration between the diabetics and non-diabetic subjects (Figure 3). However, records of bedtime and waking time were based in the present study on information provided by the subjects, and therefore the sleep duration may be inaccurate.

Previous studies reported that both short $(<5 \mathrm{~h})$ and long ( $>9 \mathrm{~h}$ ) sleepers as well as those with sleep loss, are at greater risk for glucose intolerance and T2DM [26-33].

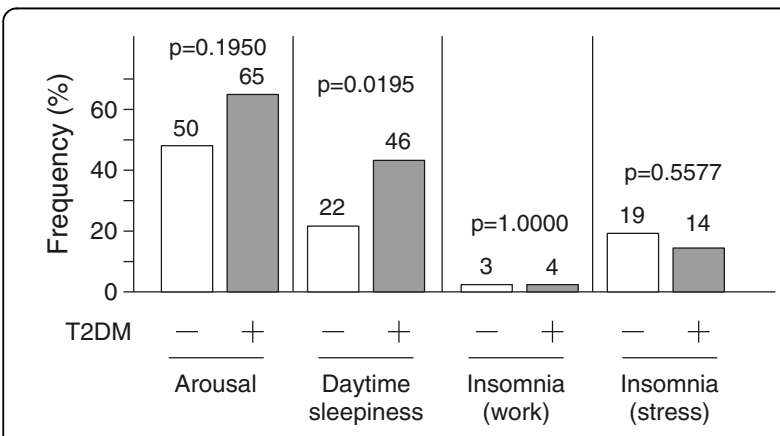

Figure 5 Comparisons of the frequency of reported arousals, daytime sleepiness, insomnia (due to work) and insomnia (due to mental stress) in subjects with type 2 diabetes mellitus (DM + ) and non-diabetic subjects (DM-).
The present study found that late bedtime $(>1: 00)$ sleepers as well as short and long sleepers had elevated HbA1c (Figure 4). Taken together, irregular sleep-wake patterns as well as short and long sleep may enhance glucose dysmetabolism.

\section{Conclusion}

The present study demonstrated late bedtime and late wake-up time, with daytime sleepiness in T2DM subjects, compared with non-T2DM subjects. Early retirement to sleep and early morning rise seems potentially simple and useful therapeutic target for diabetes.

\section{Study limitations}

There are several limitations to this study. First, all outpatients in this study were Japanese and any differences from other ethnicities are unknown. Second, there is bias in single center studies. Our study included only a limited number of subjects and further multi-center studies of larger samples should be conducted in the future. Finally, the percentage of non-employees among diabetics was $23.0 \%$ $(\mathrm{n}=17 / 74)$, compared to those among non-diabetics $(\mathrm{n}=5 /$ $32,15.6 \%$ ) (Table 1), although there was no significant difference between two groups $(p=0.4824)$. Diabetics often perform the capillary blood sugar self-test before go to bed. These points may influence the results.

\section{Abbreviations}

$\mathrm{HbA1c}$ : hemoglobin A1c; HDL-C: high-density lipoprotein-cholesterol; LDL-C: low-density lipoprotein-cholesterol; T2DM: type 2 diabetes mellitus.

\section{Competing interests}

Ken Kishida and Tohru Funahashi are members of the "Department of Metabolism and Atherosclerosis", a sponsored course endowed by Kowa Co. Ltd. and a company researcher is dispatched to the course. All other authors declare no competing interests. 


\section{Acknowledgements}

The authors thank Mr. Maki Okamoto and Nakai Hironori for the excellent technical assistance. This research was supported in part by a Grant-in-Aid for Scientific Research No. (C) 21591177 (to K.K.) and a Grant-in-Aid for Scientific Research on Innovative Areas (Research in a proposed research area) "Molecular Basis and Disorders of Control of Appetite and Fat Accumulation" ( \#22126008, to T.F. and K.K.).

\section{Authors' contributions}

TN-M and KK analyzed the data and wrote the manuscript. KK also recruited and collected data from the patients, and participated in the concept and design of the study, interpretation of data and reviewed/edited the manuscript. TF and IS contributed to the discussion and wrote the manuscript. All authors read and approved the final version of the manuscript.

\section{Received: 9 March 2012 Accepted: 2 May 2012}

Published: 2 May 2012

\section{References}

1. Preston BT, Capellini I, McNamara P, Barton RA, Nunn CL: Parasite resistance and the adaptive significance of sleep. BMC Evol Biol 2009, 9:7.

2. Resnick HE, Redline S, Shahar E, Gilpin A, Newman A, Walter R, Ewy GA, Howard BV, Punjabi NM, Sleep Heart Health Study: Diabetes and sleep disturbances: findings from the Sleep Heart Health Study. Diabetes Care 2003, 26:702-709.

3. Kawakami N, Takatsuka N, Shimizu H: Sleep disturbance and onset of type 2 diabetes. Diabetes Care 2004, 27:282-283.

4. Buxton OM, Pavlova M, Reid EW, Wang W, Simonson DC, Adler GK: Sleep restriction for 1 week reduces insulin sensitivity in healthy men. Diabetes 2010, 59:2126-2133.

5. Knutson KL, Van Cauter E: Associations between sleep loss and increased risk of obesity and diabetes. Ann N Y Acad Sci 2008, 1129:287-304.

6. Tasali E, Leproult R, Ehrmann DA, Van Cauter E: Slow-wave sleep and the risk of type 2 diabetes in humans. Proc Natl Acad Sci USA 2008, 105:1044-9.

7. Leproult R, Van Cauter E: Role of sleep and sleep loss in hormonal release and metabolism. Endocr Dev 2010, 17:11-21.

8. Buijs RM, Scheer FA, Kreier F, Yi C, Bos N, Goncharuk VD, Kalsbeek A: Organization of circadian functions: interaction with the body. Prog Brain Res 2006, 153:341-360.

9. Sack RL, Blood ML, Lewy AJ: Melatonin rhythms in night shift workers. Sleep 1992, 15:434-441

10. Roden M, Koller M, Pirich K, Vierhapper H, Waldhauser F: The circadian melatonin and cortisol secretion pattern in permanent night shift workers. Am J Physiol 1993, 265:R261-267.

11. Knutsson A: Health disorders of shift workers. Occup Med (Lond) 2003, 53:103-108.

12. Kohsaka A, Bass J: A sense of time: how molecular clocks organize metabolism. Trends Endocrinol Metab 2007, 18:4-11.

13. Scheer FA, Hilton MF, Mantzoros CS, Shea SA: Adverse metabolic and cardiovascular consequences of circadian misalignment. Proc Natl Acad Sci USA 2009, 106:4453-4458.

14. Rüger M, Scheer FA: Effects of circadian disruption on the cardiometabolic system. Rev Endocr Metab Disord 2009, 10:245-260

15. Bass J, Takahashi JS: Circadian integration of metabolism and energetics. Science 2010, 330:1349-1354

16. Huang W, Ramsey KM, Marcheva B, Bass J: Circadian rhythms, sleep, and metabolism. J Clin Invest 2011, 121:2133-2141

17. Hirata A, Kishida K, Hiuge-Shimizu A, Nakatsuji H, Funahashi T, Shimomura I: Qualitative score of systemic arteriosclerosis by vascular ultrasonography as a predictor of coronary artery disease in type 2 diabetes. Atherosclerosis 2011, 219:623-629.

18. Turek FW, Joshu C, Kohsaka A, Lin E, Ivanova G, McDearmon E, Laposky A, Losee-Olson S, Easton A, Jensen DR, Eckel RH, Takahashi JS, Bass J: Obesity and metabolic syndrome in circadian Clock mutant mice. Science 2005, 308:1043-1045.

19. Shimba S, Ishii N, Ohta Y, Ohno T, Watabe Y, Hayashi M, Wada T, Aoyagi T, Tezuka M: Brain and muscle Arnt-like protein-1 (BMAL1), a component of the molecular clock, regulates adipogenesis. Proc Natl Acad Sci USA 2005, 102:12071-12076.
20. Kondratov RV, Kondratova AA, Gorbacheva VY, Vykhovanets OV, Antoch MP: Early aging and age-related pathologies in mice deficient in BMAL1, the core componentof the circadian clock. Genes Dev 2006, 20:1868-1873.

21. Woon PY, Kaisaki PJ, Bragança J, Bihoreau MT, Levy JC, Farrall M, Gauguier D: Aryl hydrocarbon receptor nuclear translocator-like (BMAL1) is associated with susceptibility to hypertension and type 2 diabetes. Proc Natl Acad Sci USA 2007, 104:14412-144127.

22. Liu C, Li S, Liu T, Borjigin J, Lin JD: Transcriptional coactivator PGC-1alpha integrates the mammalian clock and energy metabolism. Nature 2007, 447:477-481.

23. Van Cauter E, Polonsky KS, Scheen AJ: Roles of circadian rhythmicity and sleep in human glucose regulation. Endocr Rev 1997, 18:716-738.

24. Spiegel K, Knutson K, Leproult R, Tasali E, Van Cauter E: Sleep loss: a novel risk factor for insulin resistance and Type 2 diabetes. J Appl Physiol 2005, 99:2008-2019.

25. Chasens ER: Obstructive sleep apnea, daytime sleepiness, and type 2 diabetes. Diabetes Educ 2007, 33:475-482.

26. Sridhar GR, Madhu K: Prevalence of sleep disturbances in diabetes mellitus. Diabetes Res Clin Pract 1994, 23:183-186.

27. Scheen AJ, Byrne MM, Plat L, Leproult R, Van Cauter E: Relationships between sleep quality and glucose regulation in normal humans. Am J Physiol 1996, 271:E261-270.

28. Ayas NT, White DP, Al-Delaimy WK, Manson JE, Stampfer MJ, Speizer FE, Patel S, Hu FB: A prospective study of self-reported sleep duration and incident diabetes in women. Diabetes Care 2003, 26:380-384.

29. Mallon L, Broman JE, Hetta J: High incidence of diabetes in men with sleep complaints or short sleep duration: a 12-year follow-up study of a middle-aged population. Diabetes Care 2005, 28:2762-2767.

30. Gottlieb DJ, Punjabi NM, Newman AB, Resnick HE, Redline S, Baldwin CM, Nieto FJ: Association of sleep time with diabetes mellitus and impaired glucose tolerance. Arch Intern Med 2005, 165:863-867.

31. Yaggi HK, Araujo AB, McKinlay JB: Sleep duration as a risk factor for the development of type 2 diabetes. Diabetes Care 2006, 29:657-661.

32. Chaput JP, Després JP, Bouchard C, Tremblay A: Association of sleep duration with type 2 diabetes and impaired glucose tolerance. Diabetologia 2007, 50:2298-2304.

33. Nakajima H, Kaneita Y, Yokoyama E, Harano S, Tamaki T, Ibuka E, Kaneko A, Takahashi I, Umeda T, Nakaji S, Ohida T: Association between sleep duration and hemoglobin A1c level. Sleep Med 2008, 9:745-52.

doi:10.1186/1758-5996-4-18

Cite this article as: Nakanishi-Minami et al: Sleep-wake cycle irregularities in type 2 diabetics. Diabetology \& Metabolic Syndrome 2012 $4: 18$

\section{Submit your next manuscript to BioMed Central and take full advantage of:}

- Convenient online submission

- Thorough peer review

- No space constraints or color figure charges

- Immediate publication on acceptance

- Inclusion in PubMed, CAS, Scopus and Google Scholar

- Research which is freely available for redistribution 